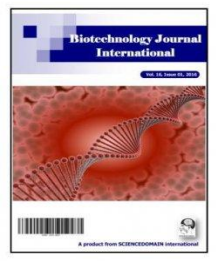

\title{
Charge Transference Detection through Cyclic Voltammograms in the Interaction of Cratylia mollis Seed Lectin-carbohydrate Inhibitor
}

\author{
Sandra Rodrigues de Souza', Edilson Gomes de Santana ${ }^{2}$, \\ José Edson Gomes de Souza ${ }^{3}$, Priscila Marcelino dos Santos Silva ${ }^{2}$, \\ Maria Tereza dos Santos Correia ${ }^{2}$ \\ and Luana Cassandra Breitenbach Barroso Coelho ${ }^{2^{\star}}$
}

\begin{abstract}
${ }^{1}$ Departamento de Educação, Universidade Federal Rural de Pernambuco, UFRPE, Rua Dom Manuel de Medeiros, S/N, Dois Irmãos, Recife-PE, CEP 52171-900, Brasil. ${ }^{2}$ Departamento de Bioquímica, Centro de Biociências, Universidade Federal de Pernambuco, UFPE, Avenida Professor Moraes Rego, S/N, Cidade Universitária, Recife-PE, CEP 50670-420, Brasil. ${ }^{3}$ Departamento de Química, Universidade Católica de Pernambuco, UNICAP, Rua do Príncipe, 526, Boa Vista, CEP 50050-900, Recife-PE, Brasil.
\end{abstract}

Authors' contributions

This work was carried out in collaboration between all authors. Author SRS designed the study, performed protocols, statistical analysis and wrote the first draft of manuscript. Authors SRS, EGS and JEGS managed the analysis of the study. Author PMSS contributed in writing the manuscript. Authors MTSC and LCBBC designed, supervised and managed the whole study. All authors read and approved the final manuscript.

Article Information

DOI: $10.9734 / \mathrm{BJI} / 2017 / 32672$ Editor(s):

(1) Chan Yean Yean, Department of Medical Microbiology and Parasitology, School of Medical Sciences, Universiti Sains Malaysia, Malaysia.

(2) Csilla Tothova, University of Veterinary Medicine and Pharmacy in Kosice, Slovakia. (3) Christopher Cullis, Francis Hobart Herrick Professor and Chair of Biology, Case Western Reserve University, USA. (4) Jayanta Kumar Patra, Assistant Professor, School of Biotechnology, Yeungnam University, Gyeongsan, Republic of Korea. (5) Prof. Kuo-Kau Lee, Department of Aquaculture, National Taiwan Ocean University, Taiwan. Reviewers:

(1) Ghada zaghloul Abbass Soliman, National Nutrition Institute, Cairo, Egypt.

(2) Teruaki Hasegawa, Toyo University, Japan. (3) Fahmida Khan, National Institute of Technology, Raipur, India. Complete Peer review History: http://www.sciencedomain.org/review-history/19458

Original Research Article

Received $9^{\text {th }}$ March 2017

Accepted $13^{\text {th }}$ June 2017

Published $14^{\text {th }}$ June 2017

\section{ABSTRACT}

Aims: To evaluate the charge transference and the electrochemical potential of Cratylia mollis seed lectin, Cramoll 1,4, adsorbed on Nafion beads after the interaction of glucose ligand.

Study Design: Based on detection of electrochemical currents and potentials of Cramoll 1,4 by

*Corresponding author: E-mail: Icbbcoelho@gmail.com; 
electrochemical techniques.

Place and Duration of Study: Department of Chemistry, Catholic University of Pernambuco, between April 2014 and November 2015.

Methodology: Cyclic Voltammetry (CV) was performed in an electrochemical cell containing three electrodes (a calomel electrode, a platinum wire counter electrode and a platinum electrode), connected to a potentiostat to obtain electrochemical currents related to the charge transference. An electrochemical cell containing a calomel electrode and a platinum electrode coupled to a multimeter was used to register the potentials. A saline solution was used as support to control the charge distribution inside of the cell. Cramoll 1,4-glucose interaction was evaluated in the concentration of 100, 200 and $300 \mathrm{mM}$ of glucose.

Results: CV measurements showed significant charge transference after Cramoll 1,4-glucose interaction. Cathodic and anodic peaks paired near $100 \mathrm{mV}$ were detected in the range 100-300 $\mathrm{mM}$ glucose, achieving a maximum current response of $1300 \mu \mathrm{A}$, approximately. Positive electrochemical potentials of Cramoll 1,4 adsorbed to Nafion-beads was achieved showing a linear behaviour with the increase of glucose concentration at $300 \mathrm{mM}$.

Conclusion: The system is useful for characterization of lectin-carbohydrate interactions and as a glucose sensor to estimate the activity of lectins.

Keywords: Cratylia mollis; cyclic voltammograms; Nafion-beads; seed lectin.

\section{INTRODUCTION}

Lectins are a group of non-immune proteins of ubiquitous distribution in nature that bind carbohydrates with high specificity [1]. Lectincarbohydrate interaction constitutes an initial biological signal to start physiological responses, such as mitogenic activity and cell-to-cell interactions [2,3]. The measurements of lectin interactions became, therefore, a highly attractive field as a quantitative method to the analysis of many biological phenomena. Lectin-carbohydrate interaction has been broadly studied through physicochemical methods such as nuclear magnetic resonance [4], surface plasmon resonance spectroscopy [5] and X-ray crystallography [6], those required complex/timeconsuming manipulations and expensive instruments. In this context, electrochemical methods have already been used to evaluate charge distribution in lectin surfaces and lectincarbohydrate interactions $[7,8]$. These methods are of fundamental importance to study macromolecular superficial charge [9] and evaluations of charged protein behaviour in analytical systems [10].

A systematic evaluation based on electrochemical methods uses potentiometric or amperometric signal transductors with small polarizable electrodes, allowing the study of surface-immobilized proteins, such as lectins, and the relationship with their ligands [11,12]. Electrochemical methods can measure directly the lectin-carbohydrate interaction through the detection of charge (electron) transference on the lectin when the interaction occurs. The electrochemical response can be measured to quantify the interaction and to characterize the behaviour of the lectin in the presence of its specific carbohydrate $[7,12]$.

Monitoring of electrochemical current evaluates lectin-carbohydrate linkage through amperometric methods, such as cyclic voltammetry (CV) [11]. CV is the electrochemical technique frequently used to characterize charge transference processes, based on scanning of the potential from the working electrode using a triangular potential waveform, and measuring the resulting current. The current is plotted versus the potential, generating a cyclic voltammogram [13]. Potentiometric methods are also useful to investigate lectin-carbohydrate interactions and the charge distribution on a lectin surface $[7,8]$. Measurements of electrochemical potential can be associated to charge transference on lectin submitted to an electric field in the presence of its ligand.

The association of lectin with polymers improves the charge transference, promoting the increase of the electrochemical signal detected [14]. Nafion is a perfluorinated anionic polyelectrolyte belonged to a class of perfluorosulfonated ionomer [15]. X-ray dispersion analysis in Nafion has revealed the presence of metallic patches and sulfonic acid groups as hydrophilic regions and fluorcarbonates as hydrophobic regions [16]. The presence of ions in the Nafion structure induces electrostatic intermolecular interactions, which confer attractive physicochemical 
properties for composition of membranes and catalyst support [17]. Available in different forms, such as membranes and beads, Nafion has been used for ion-exchange applications and electrocatalyses in electrochemical analyses due to high electrical conductivity, good stability and biocompatibility $[17,18]$. Additionally, the sulfonic acid groups of Nafion structure promote the stable biomolecule immobilization on solid surface [19].

Cratylia mollis is a native forage from the Caatinga biome of the State of Pernambuco, Northeast of Brazil. A lectin specific to glucose and mannose from $C$. mollis seed named Cramoll has been purified and sequenced $[20,21]$. Lectin-ligand interactions involving the lectin containing its isoforms 1 and 4 (Cramoll $1,4)$ have been evaluated by electrochemical techniques $[7,8]$. Biosensing approaches based in Cramoll 1,4 interactions have been developed for sugar detection in solution [11] and for recognition interface for dengue virus serotypes [22], bacterial lipopolysaccharide [23] and differential diagnostic of prostatic tumour [11]. Proteins adsorbed to polymers should leave available active binding sites, which promote the interaction with selective ligands. In this work, CV measurements and determination of electrochemical potentials were performed to analyse the charge transference signals of Cramoll 1,4 adsorbed to Nafion-beads interacting with different concentrations of glucose, in order to evaluate Cramoll 1,4 activity.

\section{MATERIALS AND METHODS}

C. mollis seeds were collected in the city of Ibimirim, in the State of Pernambuco, Northeast of Brazil. Glucose and Nafion $\left({ }^{\circledR}\right.$ NR 50 were purchased from Sigma Aldrich (St. Louis, MO, USA). Other reagents used were of analytical grade. All solutions were prepared with ultrapure water from a Milli-Q system (Billerica, USA).

\subsection{Cramoll 1,4 Obtention}

Cramoll 1,4 was isolated from C. mollis seeds according to Correia and Coelho (1995) [20]. The lectin was extracted from $C$. mollis seed flour in $0.15 \mathrm{M} \mathrm{NaCl}(10 \% \mathrm{w} / \mathrm{v})$, overnight at $4^{\circ} \mathrm{C}$. The saline extract was submitted to fractionation with ammonium sulfate and the precipitate of the 40$60 \%$ fraction was ressuspended, dialysed in saline (F40-60) and purified by affinity chromatography on Sephadex G-75. The lectin containing the isoforms 1 and 4 of Cramoll
(Cramoll 1,4) was eluted from Sephadex G-75 column with $0.3 \mathrm{M}$ glucose in $0.15 \mathrm{M} \mathrm{NaCl}$ [20] and was adsorbed on Nafion-beads surface.

\subsection{Preparation of Cramoll 1,4/Nafion- beads}

In order to adsorb Cramoll 1,4 on Nafion-beads surface, $2 \mathrm{~g}$ of Nafion ${ }^{\circledR} \mathrm{NR} 50$ beads and $3 \mathrm{ml}$ of Cramoll 1,4 in $0.15 \mathrm{M} \mathrm{NaCl}$ solution $(1 \mathrm{mg} / \mathrm{ml})$ were mixed and kept at rest for $6 \mathrm{~h}$ at $4^{\circ} \mathrm{C}$. Following, the supernatant was removed and beads were washed with $0.15 \mathrm{M} \mathrm{NaCl}$, to obtain Cramoll 1,4/Nafion-beads.

\subsection{Electrochemical Measurements of the Cramoll 1,4-glucose Interactions}

The electrochemical evaluation of Cramoll 1,4-glucose interactions was performed in an electrochemical cell containing Cramoll $1,4 /$ Nafion-beads deposited at the bottom, and $0.15 \mathrm{M} \mathrm{NaCl}$ solution as reaction media to control the distribution of charges within electrochemical cell. The measurement of electrochemical current by $\mathrm{CV}$ technique was carried out using a three-electrode system in the electrochemical cell, containing a platinum electrode $\left(A=2 \mathrm{~cm}^{2}\right)$ as the working electrode, a platinum wire as auxiliary electrode and a calomel saturated electrode as reference electrode (Fig. 1). The system was coupled to an EG\&G PAR model 175 potentiostat/ galvanostat (New Jersey, USA) connected and controlled by a microcomputer. CV technique was performed in a potential range of 50 to $150 \mathrm{mV}$ within $0.15 \mathrm{M} \mathrm{NaCl}$ solution.

In order to obtain electrochemical potentials, it was used an electrochemical cell containing a platinum electrode (working electrode) and a calomel electrode (reference electrode) coupled to a high impedance multimeter (ICEL IK-1500). The saturated calomel electrode was used since it had a stable potential in relation to temperature $\left(27^{\circ} \mathrm{C}\right)$, without variations due to charges in the medium. Electrochemical measurements were made in the absence and presence of glucose after $30 \mathrm{~min}$ of incubation. Cramoll $1,4 /$ Nafion-beads $(1 \mathrm{~g})$ into the cells were incubated with saline solutions containing glucose at concentrations of $0,100,200$ and $300 \mathrm{mM}$ were performed (Fig. 1). Each experiment was performed in five repetitions. 

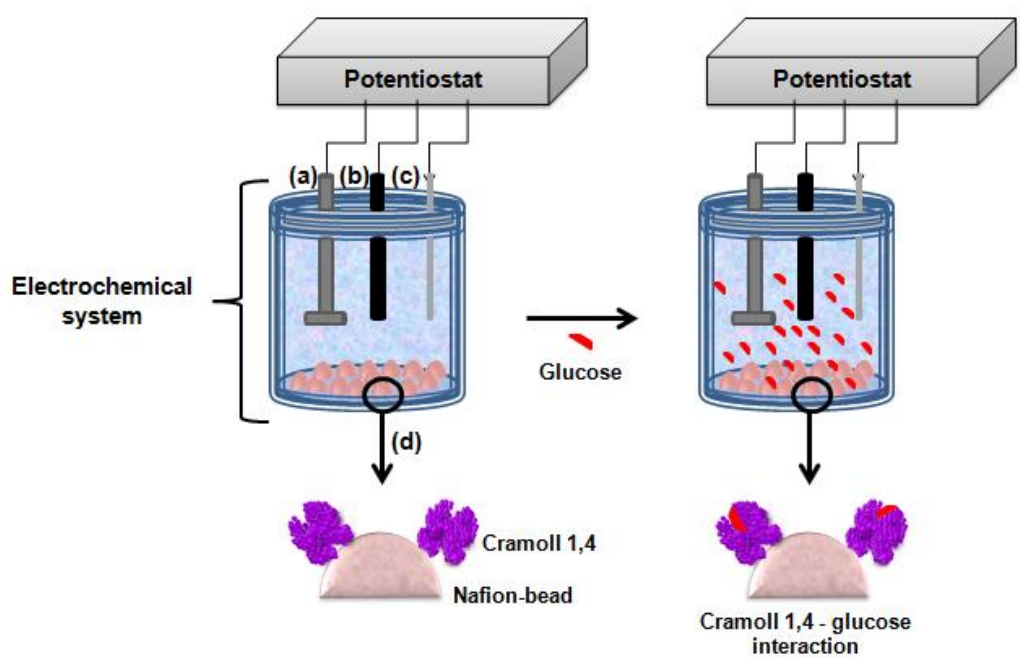

Fig. 1. Schematic representation of the electrochemical system coupled to a potentiostat for voltammetric measurements of Cramoll 1,4/Nafion-beads and glucose interactions, composed by a platinum electrode (a) as a working electrode; a saturated calomel electrode (b) as a reference electrode; an auxiliary electrode (c) and Cramoll 1,4/Nafion-beads (d)

\section{RESULTS AND DISCUSSION}

Cramoll 1,4 was isolated from C. mollis seeds by extraction of powder in $0.15 \mathrm{M} \mathrm{NaCl}$ and the precipitate obtained by ammonium sulfate fractionation was chromatographed through Sephadex G-75, according to the procedure described by Correia and Coelho [20]. Cramoll 1,4 elution with $0.3 \mathrm{M}$ glucose generated the chromatogram and electrophoretic pattern in denatured SDS-polyacrylamide gel showed in Fig. 2, in agreement with results reported by the cited authors [20].

Proteins with electroactive sites like the heme group [24] and lectins [7,8] interact with molecules or macromolecules involving charge transference. The interaction measurements of a protein adsorbed to a non-reactive surface and its ligand indicate the capacity of the macromolecule as a redox receptor, with all binding potential directed by the receptor oxidation state [10]. This property of interaction constitutes a basic tool to electrochemical measurements [25]. Firstly, the immobilization of Cramoll 1,4 on the Nafion-beads surface was evaluated through measurements of redox potentials $(+E, m V$ ) versus time (from 0 to 80 $\mathrm{min}$ ) to confirm this immobilization. As showed in Fig. 3 , an exponential increasing curve of potentials from Nafion-beads without Cramoll 1,4 was detected, while a decay time was observed for Cramoll 1,4/Nafion-beads, indicating the immobilization of Cramoll 1,4 on Nafion-beads surface and a reduction in the exposition of superficial charges of Nafion-beads.

In this work, the charge transference from Cramoll 1,4-glucose interaction was detected on the surfaces of Nafion-beads at the bottom of the electrochemical system, but not at the electrode surface (Fig. 1). When the system is submitted to an electric field caused by the working and reference electrodes in the electrolytic medium containing Cramoll 1,4 immobilized on Nafionbeads and glucose, the charge transference of Cramoll 1,4-glucose interaction is detected through electrochemical signals from direct charge exchange of lectin $[7,8]$. The $\mathrm{CV}$ method has been broadly used for charge transference detection in redox systems involving proteins and their interaction with ligands, due to more userfriendly and low cost. The electroactive properties from Cramoll 1,4 binding sites results in the charge transference during the interaction with glucose revealed by induction of redox peaks observed in CV measurements, performed in $0.15 \mathrm{M} \mathrm{NaCl}$ solution media. As shown in Fig. 4, the cyclic voltammograms obtained with Cramoll 1,4/Nafion-beads revealed well-defined states of oxi-reduction at $100 \mathrm{mV}$, represented by two reversible oxidative (anodic) and reductive (cathodic) redox peaks after interaction with glucose, showing that Cramoll 1,4/Nafion-beads glucose complex can be detected at this potential. 


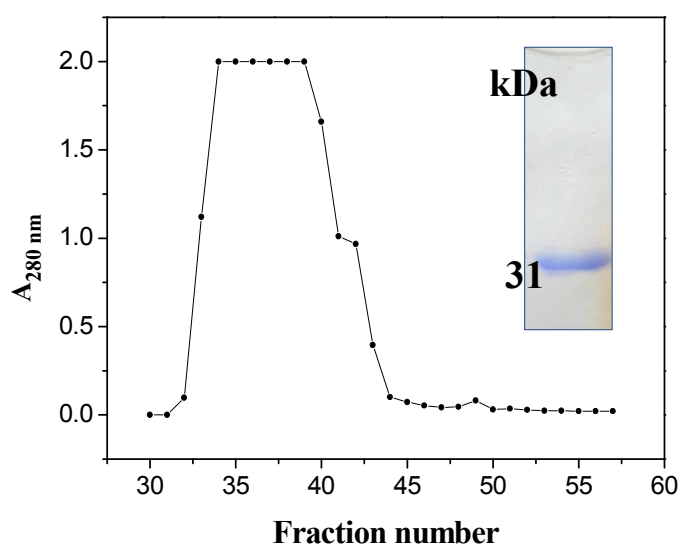

Fig. 2. Purification and partial characterization of Cramoll 1,4. Affinity chromatography of an ammonium sulfate fraction dialysed in $0.15 \mathrm{M} \mathrm{NaCl}(\mathrm{F} 40-60)$ was performed on a Sephadex G75 column in a flow rate of $30 \mathrm{~mL} / \mathrm{h}$ and $5 \mathrm{~mL}$ fractions were collected. Cramoll 1,4 was eluted with $0.3 \mathrm{M}$ glucose in $0.15 \mathrm{M} \mathrm{NaCl}$ (875 $\mathrm{mg}$ of protein). The inset shows a denatured SDS-PAGE of Cramoll 1,4 stained with Coomassie Brilliant Blue

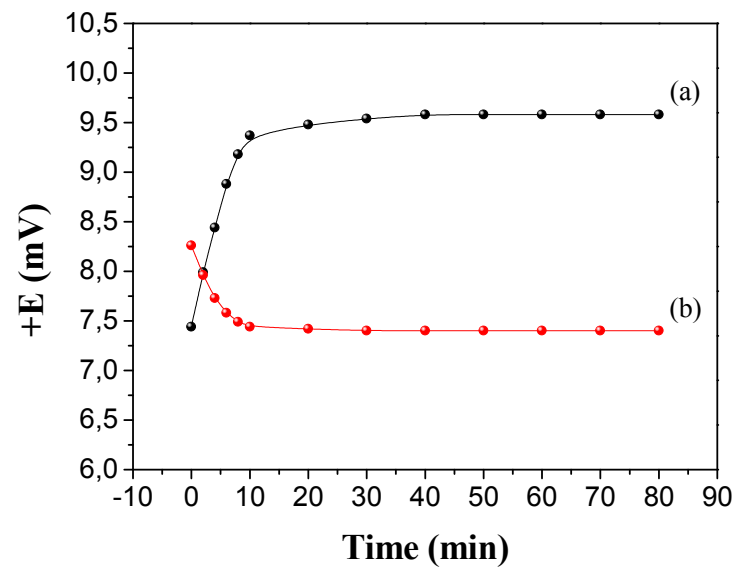

Fig. 3. Measurements of redox potentials versus time for Nafion-beads (a) and Cramoll $1,4 /$ Nafion-beads (b)

The higher cathodic current response was nearly $1300 \mu \mathrm{A}$ in the presence of $100-300 \mathrm{mM}$ glucose. Cyclic voltammograms of Cramoll $1,4 /$ Nafion-beads in the absence of glucose did not induce redox peaks. Moreover, the expression of oxi-reduction peaks at $100 \mathrm{mV}$ showed at the CV indicates that Cramoll 1,4 activity was maintained after the adsorption on Nafion-beads. Previous results using potentiometric techniques showed similar electrochemical potential of the interaction between Cramoll 1,4 and glucose in $0.15 \mathrm{M}$ $\mathrm{NaCl}$, of $94 \mathrm{mV}$ [7]. The charge transference of horseradish peroxidase enzyme immobilized on carbon paste electrode was also monitored by $\mathrm{CV}$, in $10-240 \mathrm{mV}$ within $0.1 \mathrm{M}$ buffer solution to identify hydrogen peroxide, showing double oxidative and revival peaks [24].

In order to analyse linearity of potentiometric response of Cramoll 1,4/Nafion-beads, potentials were measured at different glucose concentrations. Positive electrochemical potentials were registered for Cramoll 1,4/Nafionbeads, as showed in Fig. 5. A potentiometric curve of potential $(+\mathrm{E} ; \mathrm{mV})$ versus glucose 
concentration $(\mathrm{mM})$ was obtained, with linearity from 0 to $300 \mathrm{mM}$, revealing a linear regression equation $+E(m V)=0.036^{*}$ [glucose] +7.059 with a correlation coefficient of $0.995(p<0.001, n=$ 4 ) in five repetitions. The detection of positive potential for Cramoll 1,4 in the absence of glucose confirms the charge distribution on Cramoll 1,4 surface and its potential redox $[7,8]$. When a system generates negative electrochemical potentials it is necessary to use chemical mediators, as signal amplifiers, working in 100 and $200 \mathrm{mV}$, lowering the action of interferents in biological media [26]. The interaction between Cramoll 1,4/Nafion-beads and carbohydrate can be a model, without mediators, to characterize the lectin-ligand interactions and to determine glucose concentrations.
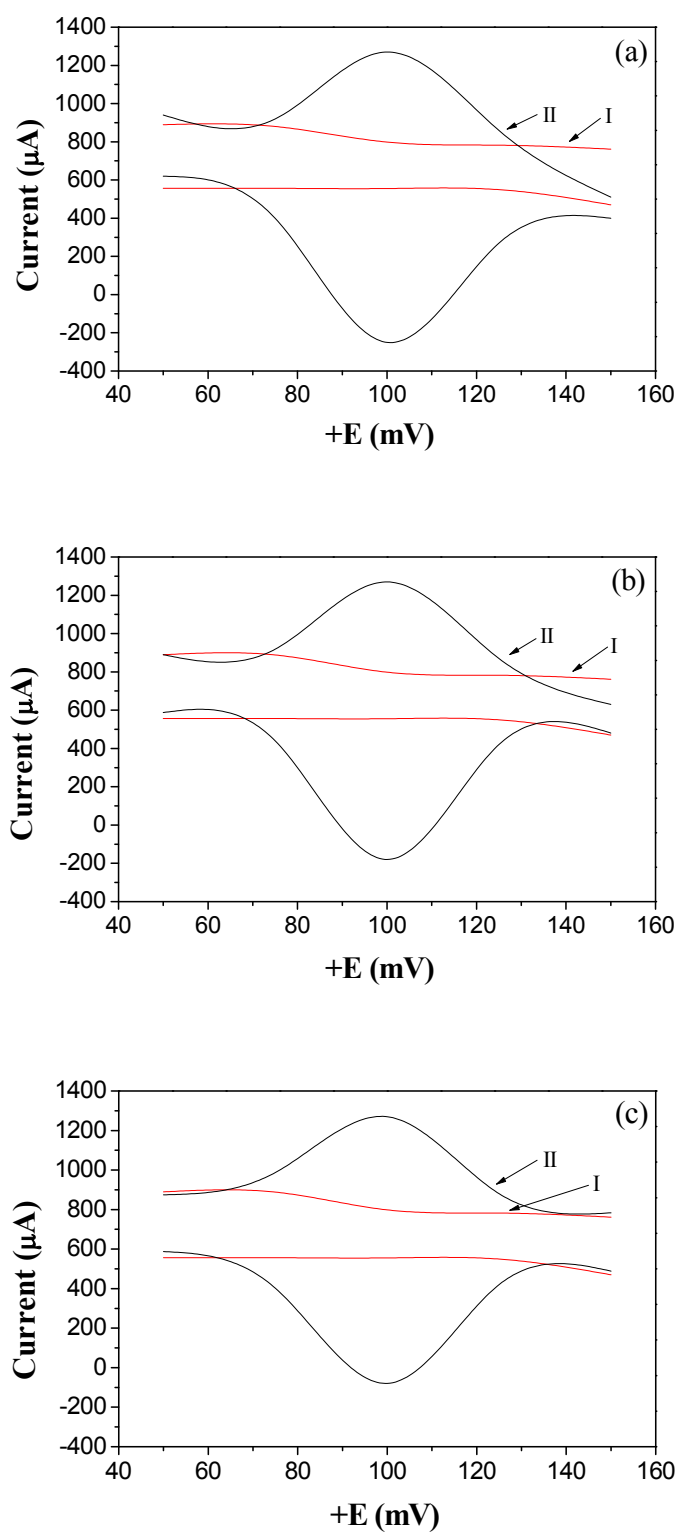

Fig. 4. Cyclic voltammetric measurements of Cramoll 1,4/Nafion-beads before (I) and after (II) interactions with different concentrations of glucose: $100 \mathrm{mM}$ (a); $200 \mathrm{mM}$ (b) and $300 \mathrm{mM}$ (c) 


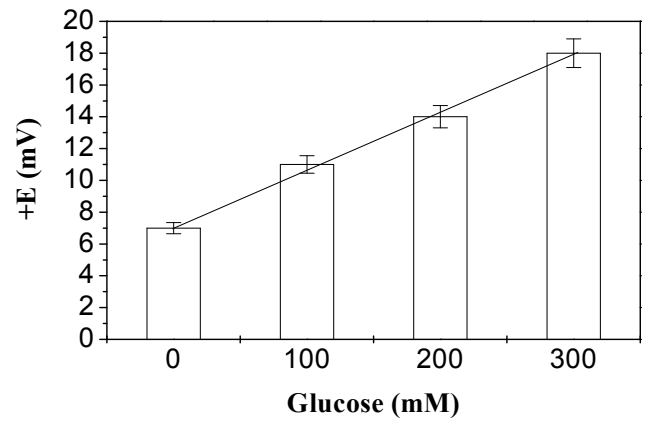

Fig. 5. Electrochemical potentials of Cramoll $1,4 /$ Nafion-beads at different glucose concentrations

\section{CONCLUSION}

The use of cyclic voltammetry allowed the detection of a redox potential of $100 \mathrm{mV}$ to Cramoll 1,4/Nafion-beads through the interaction with different glucose concentrations and constitutes another approach to determine Cramoll 1,4 activity. Electrochemical potential measurements generate a linear response for glucose concentrations, being an alternative for glucose sensing. Charge transference of lectins is a great phenomenon to evaluate lectin-carbohydrate interactions in biological systems.

\section{ACKNOWLEDGEMENTS}

The authors express their gratitude to the Conselho Nacional de Desenvolvimento Científico e Tecnológico (CNPq) for research grants; MTSC and LCBBC are grateful to fellowships.

\section{COMPETING INTERESTS}

Authors have declared that no competing interests exist.

\section{REFERENCES}

1. Santos AFS, da Silva MDC, Napoleão TH, Paiva PMG, Correia MTS, Coelho LCBB. Lectins: Function, structure, biological properties and potential applications. Curr Top Pept Protein Res. 2014;15:41-62.

2. Carvalho EVMM, Araújo-Filho VS, Nakazawa M, Gomes YM, Coelho LCBB, Correia MTS. Mitogenic activity of Cratylia mollis lectin on human lymphocytes. Biologicals. 2003;32:57-60.

DOI: 10.1016/j.biologicals.2003.12.001

3. Rabinovich GA, Croci DO. Regulatory circuits mediated by lectin-glycan interactions in autoimmunity and cancer. Immunity. 2012;36(3):322-35.

DOI: 10.1016/j.immuni.2012.03.004

4. Nagae M, Yamaguchi Y. Threedimensional structural aspects of proteinpolysaccharide interactions. Int J Mol Sci. 2014; 15:3768-83.

DOI:10.3390/ijms15033768

5. Bhattarai JK, Sharma A, Fujikawa K, Demchenko AV, Stinea KJ. Electrochemical synthesis of nanostructured gold film for the study of carbohydrate-lectin interactions using localized surface plasmon resonance spectroscopy. Carbohydr Res. 2015;405: 55-65.

DOI: 10.1016/j.carres.2014.08.019

6. Shetty KN, Latha VL, Rao RN, Nadimpall SK, Suguna K. Affinity of a galactosespecific legume lectin from Dolichos lablab to adenine revealed by X-Ray cystallography. IUBMB. 2013;65(7):63344.

DOI: 10.1002/iub.1177

7. Souza SR, Correia MTS, Pessoa MMA, Kennedy JF, Lima-Filho JL, Coelho LCBB. A novel model to characterize the electric double layer of lectins form Cratylia mollis (Camaratu bean) and Canavalia ensiformes adsorbed on metallic surface. Carbohydr Polym. 2001;46:191-3.

8. Souza SR, Dutra RF, Correia MTS, Pessoa MMA, Lima-Filho JL, Coelho LCBB. Electrochemical potential of free and immobilized Cratylia mollis seed lectin. Bioresource Technol. 2003;88:255-8.

DOI: 10.1016/S0960-8524(03)00011-7

9. Grodick MA, Muren NB, Barton JK. DNA charge transport within the cell. Biochemistry. 2015;54(4):962-73.

DOI: $10.1021 / \mathrm{bi501520w}$

10. Li SJ, Chen TW, Xia N, Hou YL, Du JJ, Liu L. Direct electrochemistry of glucose oxidase on sulfonated graphene/gold nanoparticle hybrid and its application to glucose biosensing. J Solid State Electrochem. 2013;17:2487-94.

DOI: $10.1007 / \mathrm{s} 10008-013-2134-z$

11. Silva PMS, Lima ALR, Silva BVM, Coelho LCBB, Dutra RF, Correia MTS. Cratylia mollis lectin nanoelectrode for differential diagnostic of prostate cancer and benign 
prostatic hyperplasia based on label-free detection. Biosens Bioelectron. 2016;85: 171-7.

DOI: 10.1016/j.bios.2016.05.004

12. Vargová V, Helma R, Palecek E, Ostatna V. Electrochemical sensing of concanavalin A and ovalbumin interaction in solution. Anal Chim Acta. 2016;935:97103.

DOI: 10.1016/j.aca.2016.06.055

13. Wang J. Analytical electrochemistry, 2nd ed. New York: Wiley-VHC; 2001.

14. Xue Y, Bao L, Xiao X, Ding L, Lei J, Ju H. Noncovalent functionalization of carbon nanotubes with lectin for label-free dynamic monitoring of cell-surface glycan expression. Anal Biochem. 2011;410:92-7. DOI: 10.1016/j.ab.2010.11.019

15. Mauritz KA, Moore RB. State of understanding of Nafion. Chem Rev. 2004;104:4535-85.

DOI: 10.1002/chin.200450273

16. Seen AJ. Nafion: An excellent support for metal-complex catalysts. J Mol Catal AChem. 2001;177:105-12.

DOI: 10.1016/S1381-1169(01)00312-0

17. Cozzi D, de Bonis C, D'Epifanio A, Mecheri B, Tavares AC, Licoccia S. Organically functionalized titanium oxide/nafion composite proton exchange membranes for fuel cells applications. J Power Sources. 2014;248:1127-32.

DOI: 10.1016/j.powsour.2013.10.070

18. García-González R, Fernández-Abedul MT, Costa-García A. Nafions $®$ modifiedscreen printed gold electrodes and their carbon nanostructuration for electrochemical sensors applications. Talanta. 2013;107:376-81.

DOI: 10.1016/j.talanta.2013.01.034

19. Hossain MF, Heo M, Shin JH, Park JY. An electrochemical enzymatic biosensor based on Au/FGs/solgel-GOx composite/ nafion. Int J Electrochem Sci. 2015;10: 6803-19.
20. Correia MTS, Coelho LCBB. Purification of a glucose/mannose specific lectin, isoform 1, from seeds of Cratylia mollis Mart. (Camaratu bean). Appl Biochem Biotechnol. 1995;55:261-73.

DOI: $10.1007 / B F 02786865$.

21. de Souza GA, Oliveira PSL, Trapani S, Santos ACD, Rosa JC, Laura $\mathrm{HJ}$, et al. Amino acid sequence and tertiary structure of Cratylia mollis seed lectin. Glycobiology. 2003;13:961-72.

DOI: 10.1093/glycob/cwg115

22. Avelino KYPS, Andrade CAS, de Melo CP, Nogueira ML, Correia MTS, Coelho LCBB, et al. Biosensor based on hybrid nanocomposite and cramoll lectin for detection of dengue glycoproteins in real samples. Synth Met. 2014;194:102-08. DOI: 10.1016/j.synthmet.2014.05.001

23. Oliveira MDL, Andrade CAS, Correia MTS, Coelho LCBB, Singh PR, Zeng $X$. Impedimetric biosensor based on selfassembled hybrid cystein-gold nanoparticles and Cramoll lectin for bacterial lipopolysaccharide recognition. J Colloid Interface Sci. 2011;362:194-201. DOI: 10.1016/j.cis.2011.06.042

24. Salavati H, Fazilati M, Behrooznam R. Study on electrochemical behavior of horseridash peroxidase enzyme by $\mathrm{MgO}$ nanoparticles modified electrode to identify hydrogen peroxide. Int $\mathrm{J}$ Electrochem Sci. 2014;9:7460-70.

25. Ahn KS, Kim BK, Lee WY. Cyclic voltammetric studies of carbohydrateprotein interactions on gold surface. Electrochem Commun. 2015;58:69-72. DOI: 10.1016/j.elecom.2015.06.008.

26. Tian F, Zhu G. Bienzymatic amperometric biosensor for glucose based on polypyrrole/ceramic carbon as electrode material. Anal Chim Acta. 2002;451:25158.

DOI: $10.1016 / s 0003-2670(01) 01405-2$

(c) 2017 Souza et al.; This is an Open Access article distributed under the terms of the Creative Commons Attribution License (http://creativecommons.org/licenses/by/4.0), which permits unrestricted use, distribution, and reproduction in any medium, provided the original work is properly cited.

Peer-review history:

The peer review history for this paper can be accessed here: http://sciencedomain.org/review-history/19458 